\title{
Yvan Lamonde et Denis Saint-Jacques, 1937: un tournant culturel
}

Jean-François Plamondon

\section{(2) OpenEdition}

10 Journals

\section{Édition électronique}

URL : http://journals.openedition.org/studifrancesi/7762

DOI : 10.4000/studifrancesi.7762

ISSN : 2427-5856

Éditeur

Rosenberg \& Sellier

\section{Édition imprimée}

Date de publication : 1 décembre 2009

Pagination : 683

ISSN : 0039-2944

\section{Référence électronique}

Jean-François Plamondon, «Yvan Lamonde et Denis Saint-Jacques, 1937: un tournant culturel », Studi Francesi [En ligne], 159 (LIII | III) | 2009, mis en ligne le 30 novembre 2015, consulté le 09 janvier 2021. URL : http://journals.openedition.org/studifrancesi/7762 ; DOI : https://doi.org/10.4000/studifrancesi. 7762

Ce document a été généré automatiquement le 9 janvier 2021.

\section{(c)}

Studi Francesi è distribuita con Licenza Creative Commons Attribuzione - Non commerciale - Non opere derivate 4.0 Internazionale. 


\title{
Yvan Lamonde et Denis Saint- Jacques, 1937: un tournant culturel
}

\author{
Jean-François Plamondon
}

\section{RÉFÉRENCE}

YVAN LAMONDE ET DENIS SAINT-JACQUES, 1937: un tournant culturel, Québec, Presses de

l’Université Laval, 2009, «Cultures québécoises», pp. 371.

1 Un soleil nouveau se lève, depuis quelques années, sur une période historique québécoise communément appelée la Grande Noirceur (1936-1959). Si la construction de la mémoire tend à envelopper cette période d'une chape de plomb, aussi lourde qu'impénétrable, de plus en plus d'études démontrent au contraire que dès les années 1930, une volonté de présenter le monde autrement prenait son élan. En d'autres mots, ce qui a précédé la Révolution tranquille (1960-1966) n'a rien à voir avec l'immobilisme d'une culture endormie, qui attend la diane de quelque héraut sauveur. Des livres majeurs comme 1937: un tournant culturel nous rappellent que là où on avait lu jusqu'à présent l'histoire d'un long fleuve tranquille, se cachaient déjà en fait les prémisses d'une révolution. Plusieurs textes importants composent ce collectif qui met au jour une période historique pleinement consciente d'appartenir à un monde en marche vers la modernité.

2 Construit en trois partie distinctes, le livre propose d'abord un texte d'Yvan LAMONDE qui ramène à la mémoire la figure de Dostaler O'Leary. Après l'avoir bien posé dans le champ intellectuel de l'époque, Lamonde cherche à comprendre «pourquoi, autour de 1937, la réflexion diversifiée sur le nationalisme n'aboutit-elle pas?» (p. 4). Puis Karim LAROSE rappelle aussi les tenants nationalistes du Deuxième Congrès de langue française au Canada, porté, selon les mots de Camille RoY, "par 'un acte de foi' collectif sans précédent» (p.15). Pour sa part, Michel воск illustre merveilleusement bien l'importance des réseaux d'influence personnaliste français d'André Laurendeau, intellectuel qui marque son époque et qui fait avancer toute une jeune génération 
attentive aux mouvements progressistes. Caroline DÉsY enchaîne en jetant une lumière sur l'accueil qu'ont réservé les journaux québécois à André Malraux et Italo Balbo, tous deux de passages à Montréal dans les années 1930. Si Malraux était envoyé de manière officieuse par la gauche espagnole, Balbo représentait l'Italie moderne et futuriste soulevée par l'idéologie fasciste. La venue de l'un et de l'autre semble avoir fait ressortir dans la presse de l'époque les tensions des champs politique et culturel qui animaient l'esprit québécois d'alors. Si on peut dire que la modernité est bien enclenchée au Québec, l'américanité ne l'est pas moins. Et toutes deux sont perçues comme des menaces identitaires par une certaine presse bien impuissante à freiner l'un et l'autre des mouvements. C'est du moins ce qui ressort de la lecture du texte de Denis SAINT-JACQUES et Marie-Josée DES RIVIÈRES pour qui les mœurs et la culture états-uniennes se sont bien propagées à tous les niveaux sociaux du Québec des années 1930 et peutêtre plus rapidement chez les femmes, avides de modernité et de consommation. Encore nombreux sont les articles qui témoignent d'une vivacité culturelle. Que ce soit d'un point de vue des arts, de la musique, de l'architecture et même du cinéma de propagande produit par des prêtres, la société québécoise s'éveillait aux moyens qui lui étaient offerts et saisissait les opportunités qui s'offraient à elle. La modernité appartient à tous et chacune des cultures lui donne une dynamique propre à son ambition. Elle avance en fonction du rythme qu'on veut bien lui donner et du projet collectif à la source duquel elle émerge. Après la lecture du livre de Lamonde et SaintJacques, personne ne pourra plus prétendre que la modernité québécoise est un fait des années 1960. Une première révolution, toute aussi tranquille, avait déjà fait ses preuves. Il ne restait qu'à institutionnaliser ce que la pratique avait déjà dessiné. 